\title{
Theoretical Analysis and Experimental Verification of the Influence of Geometrical Parameters on the Fatigue Life of SMA490BW Welded Butt Joint
}

\author{
Bolin $\mathrm{HE}^{1}$, Yongxiang WANG, Yingxia YU, Yuxin ZHANG and Kang WEI \\ College of Material Science and Engineering, East China Jiaotong University, \\ Nanchang 330013, China
}

\begin{abstract}
Finite element mode was carried out for ultra-high cycle fatigue specimens of SMA490BW steel butt joints used in bogies. Finite element software ABAQUS/ FE-Safe was used to calculate the influences of different arc transition radius $r$ and weld toe angles $\theta$ on joint stress concentration factor $K_{t}$ and joint fatigue life $N$. The results show that $r$ and $\theta$ have significant influence on the $K_{t}$ and fatigue life of the SMA490BW steel butt joint for bogie. For the same inclination angle $\theta, K_{t}$ decreases gradually with $r$ increasing. With $\theta$ increases, the effect of $r$ on $K_{t}$ is increasing continuously, also the effect of change in $K_{t}$ caused by $\mathrm{r}$ on fatigue life $\mathrm{N}$ is increasing continuously. While in the case of same weld edge $r, K_{t}$ increases with $\theta$ increasing. With $r$ increases, the effect of $\theta$ on $K_{t}$ is decreasing constantly, the effect of change in $K_{t}$ caused by $\theta$ on fatigue life $N$ is decreasing constantly. The fatigue performance of SMA490BW steel butt joint was tested by ultrasonic fatigue test machine. The results between the fatigue test and calculation is less than $15 \%$. The finite element calculation result has important significance for improving the fatigue life of welded butt joint for bogie.
\end{abstract}

Keywords. butt joint, stress concentration factor, weld toe, finite element

\section{Introduction}

Since the beginning of the 21 st century, with the development of China railway transportation towards high-speed passenger transport, heavy freight transport and large volume, the requirements for the safety, reliability and comfort of high-speed train operation have also been continuously improved. Fatigue failure is the main form of welded structure failure. $90 \%$ of welded structure failure accidents are caused by fatigue fracture of welded joints [1,2].

In order to meet the development needs of my country's railways towards high speed and heavy load, higher requirements are put forward for the fatigue performance of bogie materials and welded components $[3,4]$. Therefore, research on how to improve the fatigue performance of bogie welded joints is of great significance to ensure the safe and reliable operation of high-speed trains. Considering the significant

\footnotetext{
${ }^{1}$ Bolin He, professor, doctoral tutor, College of Material Science and Engineering, East China Jiaotong University; E-mail: hebolin@163.com.
} 
influence of the $\mathrm{K}_{\mathrm{t}}$ at the weld toe on the fatigue life of the bogie welded joints, this paper applies the finite element software ABAQUS/FE-SAFE to calculate $\mathrm{K}_{\mathrm{t}}$ and fatigue of the high-cycle fatigue specimens of the SMA490BW steel butt joint for bogies. Calculation of life. In the calculation, $\mathrm{r}$ is increased from $0.2 \mathrm{~mm}$ to $4 \mathrm{~mm}$, and $\theta$ is change $10^{\circ}$ into $60^{\circ}$. The fatigue performance of the SMA490BW steel butt joint was tested by an ultrasonic fatigue testing machine, and the fatigue test results and the finite element calculation results were compared and analyzed.

\section{Experiment}

\subsection{Establishment of Finite Element Model}

This paper uses the hexahedral element in the finite element software ABAQUS to divide the mesh. In order to improve the convergence speed and calculation accuracy of the analysis, the quadratic element C3D20 is used. At the same time, the mesh is refined in the weld toe area where the stress is concentrated, and the mesh far away from this area can be appropriately larger to reduce the scale of the control model. The result of the finite element meshing is shown in Figure 2. The minimum element size is $0.05 \mathrm{~mm}$, the elastic modulus of the material is $\mathrm{E}=206 \mathrm{GPa}$, and the Poisson's ratio $\mu=0.3$. Establish model boundary conditions, the left end of the specimen is completely fixed, and a uniform tensile load of $50 \mathrm{MPa}$ is applied to the right end.

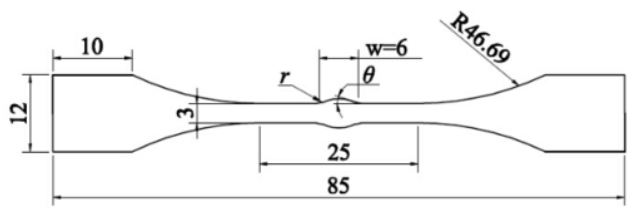

(a)Front view

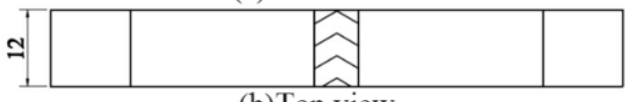

(b)Top view

Figure 1. Shapes and dimensions of butt joint

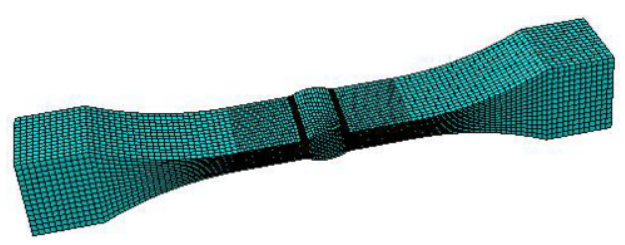

Figure 2. Finite element mesh of butt joint model

\subsection{Calculation Results and Analysis of Stress Concentration Factor for Butt Joints}

In order to comprehensively investigate the influence of $\theta$ and $r$ on the $K_{t}$ at the weld toe, In the finite element calculation, the specific design values of the parameters are shown in Table 1. The $\mathrm{K}_{\mathrm{t}}$ at the weld toe is the ratio of the maximum stress at the weld 
toe to the average stress of the section. Figure 3 is the main stress cloud diagram of the butt joint with $\mathrm{r}=1.5$ and $\theta=30^{\circ}$. The obtained $\mathrm{K}_{\mathrm{t}}$ is 1.419 .

Table 1. Geometry parameters range of weld toe

\begin{tabular}{rrrrrrrrrrr}
\hline \multicolumn{1}{r|}{ Parameter } & \multicolumn{1}{c}{ Specific design value } \\
\hline$\theta /\left(^{\circ}\right)$ & 10 & 20 & 30 & 40 & 50 & 60 & \\
$\mathrm{r} / \mathrm{mm}$ & 0.2 & 0.5 & 1 & 1.5 & 2 & 2.5 & 3 & 4 \\
\hline
\end{tabular}

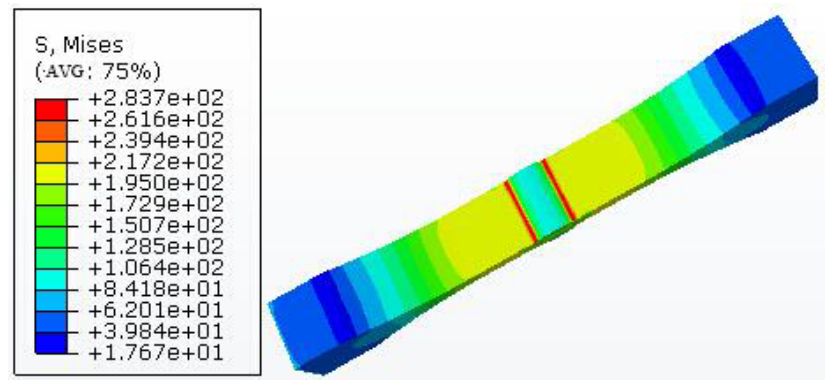

Figure 3. Principal stress contours of butt joint $\left(r=1.5 \mathrm{~mm}, \theta=30^{\circ}\right)$

Using the same grid unit and the same loading conditions., Obtain the stress distribution diagram of the butt joint corresponding to other parameters, Table 2 shows the calculation results of the $\mathrm{K}_{\mathrm{t}}$.

Table 2. Influence of geometrical parameters on stress concentration factor of welded joints

\begin{tabular}{|c|c|c|c|c|c|c|}
\hline \multicolumn{7}{|l|}{$\theta<($ degree $)$} \\
\hline $\mathrm{r}(\mathrm{mm})$ & 10 & 20 & 30 & 40 & 50 & 60 \\
\hline 0.2 & 1.391 & 1.747 & 1.976 & 2.263 & 2.425 & 2.525 \\
\hline 0.5 & 1.305 & 1.597 & 1.763 & 1.876 & 1.944 & 1.990 \\
\hline 1 & 1.288 & 1.443 & 1.535 & 1.591 & 1.621 & 1.636 \\
\hline 1.5 & 1.241 & 1.356 & 1.419 & 1.451 & 1.467 & 1.472 \\
\hline 2 & 1.215 & 1.304 & 1.345 & 1.368 & 1.378 & 1.381 \\
\hline 2.5 & 1.194 & 1.265 & 1.306 & 1.306 & 1.312 & 1.315 \\
\hline 3 & 1.178 & 1.234 & 1.257 & 1.263 & 1.265 & 1.266 \\
\hline 4 & 1.152 & 1.190 & 1.201 & 1.203 & 1.208 & 1.213 \\
\hline
\end{tabular}

According to the Table 2, the stress concentration is relatively large at the weld toe, and $\theta$ has a significant effect on the $K_{t}$ of the joint. In the case of the same $r$, the $K_{t}$ increases with the increase of $\theta$. Take the $\mathrm{r}=0.2 \mathrm{~mm}$ as an example, and use origin software to fit the first-order exponential curve to the data. The equation of the fitted curve is:

$$
K t=2.966-2.04 e^{(-\theta / 39.129)} \text { (The unit of } \theta \text { is degrees, } \theta \text { varies between } 10^{\circ} \text { to } 60^{\circ} \text { ) }
$$

When $\theta$ change $10^{\circ}$ into $60^{\circ}$, the $\mathrm{K}_{\mathrm{t}}$ change 1.391 into 2.525 , an increase of $81.52 \%$. when $\mathrm{r}$ is $0.5,1,1.5,2,2.5,3,4 \mathrm{~mm}$, the corresponding increase in $\mathrm{K}_{\mathrm{t}}$ is $52.49 \%, 27.02 \%, 18.61 \%, 13.66 \%, 10.13 \%, 7.47 \%, 5.3 \%$. This shows that with the continuous increase of the $r$, the influence of $\theta$ on the stress concentration is continuously reduced.

According to the Table 2 that the $\mathrm{r}$ of the weld toe transition also has a great influence on the $\mathrm{K}_{\mathrm{t}}$ of the joint. For the same weld toe inclination angle $\theta$, the $\mathrm{K}_{\mathrm{t}}$ gradually decreases with the increase of the $\mathrm{r}$. Take $\theta=30^{\circ}$ as an example, and use 
Origin software to fit the data with a third-order exponential curve. The $\mathrm{K}_{\mathrm{t}}$ and the weld toe transition arc in this case are obtained. The relational expression between the radii $r$ is as follows:

$$
K t=1.112 e^{-r / 37.37}+1.075 e^{-r / 38.137}+0.764 e^{-r / 0.686}-0.769(\mathrm{r}=0.2 \sim 4 \mathrm{~mm})
$$

According to Table 2 that when the $\mathrm{r}$ changes in the interval of $0.2 \sim 2 \mathrm{~mm}, \mathrm{~K}_{\mathrm{t}}$ drops rapidly, and changing $r$ is very effective in reducing the stress concentration. When $r$ changes in the interval of 2 to $4 \mathrm{~mm}$, although the stress concentration can also be reduced, $\mathrm{K}_{\mathrm{t}}$ drops gently. The $\mathrm{r}$ increased from $0.2 \mathrm{~mm}$ to $2 \mathrm{~mm}$, and the $\mathrm{K}_{\mathrm{t}}$ decreased from 1.976 to 1.345 , a decrease of $31.93 \%$; When the $\mathrm{r}$ increases from $2 \mathrm{~mm}$ to $4 \mathrm{~mm}$, the $\mathrm{K}_{\mathrm{t}}$ decreases from 1.345 to 1.201 , a decrease of $10.70 \%$.

When $\theta$ is $30^{\circ}$, The radius $r$ of the weld toe transition arc changed from $0.2 \mathrm{~mm}$ to $4 \mathrm{~mm}$, and the $\mathrm{K}_{\mathrm{t}}$ dropped from 1.976 to 1.201 , and the overall decrease was $39.22 \%$; When $\theta$ is $10^{\circ}, 20^{\circ}, 40^{\circ}, 50^{\circ}, 60^{\circ}$, the corresponding $\mathrm{K}_{\mathrm{t}}$ decreases in order by $17.18 \%$, $31.88 \%, 46.84 \%, 50.19 \%, 51.96 \%$, This shows that with the increase of $\theta$, the influence of $r$ at the weld toe on the stress concentration is increasing.

\section{Results}

\subsection{Calculation Results and Analysis of Fatigue Life of Butt Joints}

FE-SAFE is a high-precision fatigue analysis software that provides a rich and advanced material database and fatigue algorithm, as well as a complex fatigue loading spectrum. The common method to predict the fatigue life of welded joints is equivalent structural stress, and it has been successfully applied to fatigue analysis of various forms of welded components. This paper calculates the fatigue life of butt joints based on the Miner cumulative damage theory. Combined with the actual load of the buttjoined specimen, the sine wave load is selected as the excitation load. The maximum excitation load is $200 \mathrm{MPa}$ and the minimum is $-200 \mathrm{MPa}$, which means the specimen is fully reversed at the loading ratio $\mathrm{R}=-1$. Undertake fatigue life research.

Import the static results calculated by ABAQUS into FE-SAFE for fatigue life analysis. Figure 4 shows the fatigue life curve of butt joints, where $r=2.0 \mathrm{~mm}, \theta=30^{\circ}$, and life $\mathrm{N}=6.04 \times 10^{5}$.

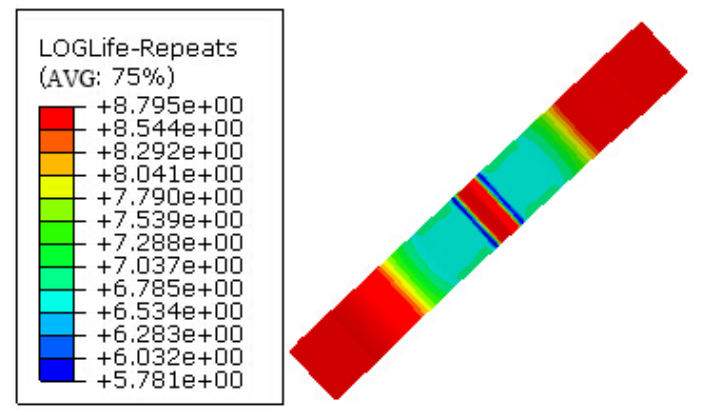

Figure 4. Fatigue life contour of joint $\left(\mathrm{r}=2.0 \mathrm{~mm}, \theta=30^{\circ}\right)$ 


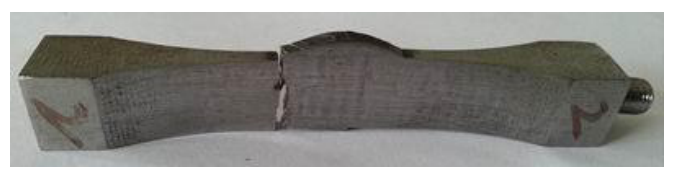

Figure 5. Fatigue fracture location of real specimen

It can be seen from Figure 4 that the fatigue life of the weld toe of the welded joint is the smallest, which is in good agreement with the static analysis result. In addition, considering only the influence of the geometrical parameters of the joint specimen, the weld toe is the weak link with the greatest stress concentration in the welded joint, which is consistent with the actual fatigue fracture position of the joint, as shown in Figure 5, Table 3 shows the calculation results of the influence of other parameters on the fatigue performance of the joint.

As can be seen from Table 3, Under different $\theta$ and $r$, the corresponding fatigue life of butt joints is obviously different. Under the same inclination angle of the weld toe, the fatigue life $\mathrm{N}$ increases with the increase of the $\mathrm{r}$. Improving the stress concentration of welded joints can effectively improve the fatigue performance of welded structures. It can be seen from Table 3 that when $\theta=30^{\circ}$ and the radius $r$ of the weld toe increases from 0.5 to $4 \mathrm{~mm}$, the stress concentration factor $\mathrm{K}_{\mathrm{t}}$ decreases from 1.763 to 1.201 , and the rate of decrease is $31.88 \%$. But the fatigue life $\mathrm{N}$ of butt joints increased from $1.12 \times 10^{5}$ to $1.35 \times 10^{6}$, and the fatigue life was extended by 12.1 times. For welded butt joints under the same fatigue loading conditions, the smaller the stress concentration factor $\mathrm{K}_{\mathrm{t}}$, the higher the fatigue life $\mathrm{N}$ and the better the fatigue performance of the welded joint.

Table 3. The fatigue life of the butt joint varies with the parameters $r$ and $\theta$

\begin{tabular}{|c|c|c|c|c|c|c|}
\hline r(mm) & 10 & 20 & 30 & 40 & 50 & 60 \\
\hline 0.2 & $4.22 \times 10^{5}$ & $1.14 \times 10^{5}$ & $5.26 \times 10^{4}$ & $2.59 \times 10^{4}$ & $1.86 \times 10^{4}$ & $1.46 \times 10^{4}$ \\
\hline 0.5 & $7.06 \times 10^{5}$ & $2.06 \times 10^{5}$ & $1.12 \times 10^{5}$ & $7.87 \times 10^{4}$ & $6.44 \times 10^{4}$ & $5.75 \times 10^{4}$ \\
\hline 1 & $8.05 \times 10^{5}$ & $3.90 \times 10^{5}$ & $2.55 \times 10^{5}$ & $2.02 \times 10^{5}$ & $1.81 \times 10^{5}$ & $1.75 \times 10^{5}$ \\
\hline 1.5 & $1.04 \times 10^{6}$ & $5.51 \times 10^{5}$ & $4.16 \times 10^{5}$ & $3.60 \times 10^{5}$ & $3.36 \times 10^{5}$ & $3.24 \times 10^{5}$ \\
\hline 2 & $1.22 \times 10^{6}$ & $7.48 \times 10^{5}$ & $6.04 \times 10^{5}$ & $5.45 \times 10^{5}$ & $5.18 \times 10^{5}$ & $5.11 \times 10^{5}$ \\
\hline 2.5 & $1.42 \times 10^{6}$ & $9.08 \times 10^{5}$ & $7.31 \times 10^{5}$ & $7.31 \times 10^{5}$ & $7.13 \times 10^{5}$ & $7.10 \times 10^{5}$ \\
\hline 3 & $1.57 \times 10^{6}$ & $1.07 \times 10^{6}$ & $9.62 \times 10^{5}$ & $9.23 \times 10^{5}$ & $9.14 \times 10^{5}$ & $9.12 \times 10^{5}$ \\
\hline 4 & $1.85 \times 10^{6}$ & $1.43 \times 10^{6}$ & $1.35 \times 10^{6}$ & $1.32 \times 10^{6}$ & $1.27 \times 10^{6}$ & $1.22 \times 10^{6}$ \\
\hline
\end{tabular}

\subsection{Fatigue Test Results of Butt Joints}

In order to compare with the theoretical calculation results, it was carried out on the USF-2000 ultrasonic fatigue testing machine produced by Shimadzu, Japan, the loading frequency was $20 \mathrm{kHz}$, and the stress ratio $\mathrm{R}$ was -1 , that is, the sample was subjected to axially symmetric tension and compression cyclic load, and the test was at room temperature $\left(25^{\circ} \mathrm{C}\right)$, the test system will automatically stop when the sample breaks, and record the corresponding data. At the same time, in order to avoid the rapid temperature rise of the sample caused by high-frequency resonance and affect the test results, compressed air is used to cool the sample. The test interval ratio is 200:600, that is, the resonance time is $200 \mathrm{~ms}$ and the interval time is $600 \mathrm{~ms}$. To compare the test fatigue life of the welded joint with the theoretically calculated fatigue life, it is required that the weld toe inclination of the test specimen and the $r$ of the weld toe are basically the same. Use normal welding specimens, and $\theta$ is about $30^{\circ}$. The radius is 
improved by the warp cutting process, and the stress is relieved and tempered at $200^{\circ} \mathrm{C}$ for $2 \mathrm{~h}$. The arc transition radius is adjusted from $\mathrm{r}$ about $0.5 \mathrm{~mm}$ to $4 \mathrm{~mm}$. The comparison between the theoretical calculation results and the fatigue test results is shown in Table 4.

Table 4. Comparison of theoretical calculation and experimental fatigue life

\begin{tabular}{llll}
\hline Sample geometry & $\begin{array}{l}\text { Fatigue life of } \\
\text { sample } \times \mathbf{1 0}^{\mathbf{6}}\end{array}$ & $\begin{array}{l}\text { Average fatigue } \\
\text { life of sample } \times \mathbf{1 0}^{\mathbf{6}}\end{array}$ & $\begin{array}{l}\text { Calculation of fatigue life by } \\
\text { finite element } \mathbf{m e t h o d} \times \mathbf{1 0}^{\mathbf{6}}\end{array}$ \\
\hline$\theta=30^{\circ}, \mathrm{r}=0.5 \mathrm{~mm}$ & 0.157 & & \\
& 0.112 & 0.126 & 0.113 \\
\hline & 0.108 & & \\
$\theta=30^{\circ}, \mathrm{r}=4 \mathrm{~mm}$ & 1.178 & 1.547 & 1.356 \\
& 1.806 & & \\
\hline
\end{tabular}

It can be seen from Table 4 that the average fatigue life of welded joint is $0.126 \times$ $10^{6}$ when the inclination angle of weld toe is $30^{\circ}$ and $\mathrm{r}$ is $0.5 \mathrm{~mm}$, and the fatigue life calculated by finite element method is $0.112 \times 10^{6}$, with a difference of $12.5 \%$; when the inclination angle of weld toe is $30^{\circ}$ and $\mathrm{r}$ is $4 \mathrm{~mm}$, the average fatigue life of welded joint is $1.547 \times 10^{6}$, and the fatigue life calculated by finite element method is $356 \times$ $10^{6}$, the difference is $14.1 \%$, In both cases, the fatigue life error of theoretical calculation and test is less than $15 \%$. The results obtained by finite element calculation have important guiding significance for improving the stress concentration factor and fatigue life of bogie welded butt joint.

\section{Discussion}

Increasing the transition arc radius of the weld toe can effectively reduce the stress concentration at the weld toe and improve the fatigue performance of the welded joint. Many scholars have carried out surface modification of welded joints by ultrasonic impact, TIG Dressing and high-energy shot peening, which verified the above argument [5-6]. He et al [7] studied the effect of ultrasonic impact on the fatigue performance of $16 \mathrm{MnR}$ steel cross joints commonly used in bogies. The results show that: after Ultrasonic impact treatment, the weld toe of the welded joint becomes smooth transition, which effectively reduces the stress concentration of the welded joint. The conditional fatigue limit of the impact cross joint is $49 \%$ higher than that of the as welded joint, and the fatigue life of the joint is extended by $45 \sim 52$ times. Pedersen et al[8] treated the weld toe of high strength steel welded joint by TIG Dressing and ultrasonic impact. Since the arc between the weld and the base metal becomes smooth after TIG repair, the increase of the arc radius reduces the stress concentration. The fatigue test results show that the fatigue strength of the welded joint is $368 \mathrm{MPa}$ under $2 \times 10^{6}$, which is far higher than 217 of the as welded sample. At the same time, the fatigue life is also improved. Therefore, reducing the stress concentration by increasing $r$ can provide a theoretical basis for the improvement of the fatigue resistance of the welded structure in technical processes such as ultrasonic impact, TIG dressing, and shot peening.

In order to comprehensively analyze the influence of $r$ and $\theta$ on the $K_{t}$, as shown in Figure 6. It can be seen that the different geometry of weld toe will lead to great difference in stress concentration factor of joint, which will affect the fatigue performance of joint. During the welding process, in order to ensure the reliability of 
the welded structure during service, the actual transition radius of the joint should be greater than $2 \mathrm{~mm}$, and the inclination angle of the weld toe should be less than $30^{\circ}$

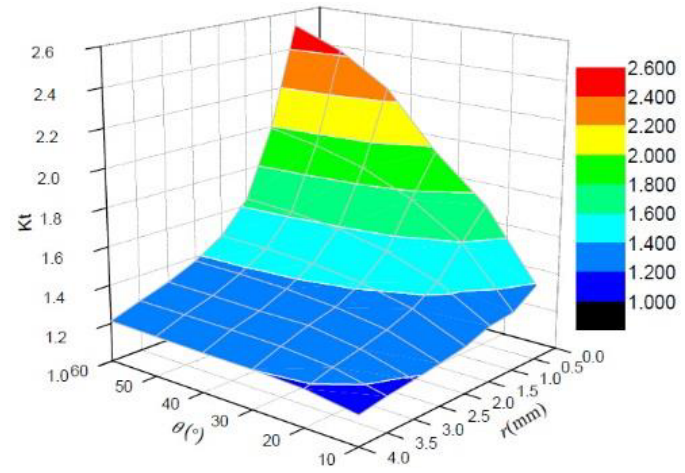

Figure 6. 3D graph for the relationship of stress concentration factor $K_{t}$ with $r$ and $\theta$

\section{Conclusion}

1) The stress concentration is relatively large at the weld toe of butt joint, and the inclination angle of weld toe has a significant effect on the stress concentration factor $\mathrm{K}_{\mathrm{t}}$. Under the condition of the same welding toe transition arc radius $\mathrm{r}$, the larger the inclination angle $\theta$ of the weld toe is, the larger $K_{t}$ will change accordingly. With the continuous increase of $r$, the influence of $\theta$ on $K_{t}$ is continuously reduced.

2) The $r$ also has a greater impact on Kt. When $\theta$ is $30^{\circ}$, the $r$ increases from 0.2 $\mathrm{mm}$ to $2 \mathrm{~mm}$, and $\mathrm{K}_{\mathrm{t}}$ decreases from 1.976 to 1.345 , a decrease of $31.93 \%$; when $\mathrm{r}$ increases from $2 \mathrm{~mm}$ to $4 \mathrm{~mm}, \mathrm{~K}_{\mathrm{t}}$ decreases from 1.345 to 1.201 , which is only $10.70 \%$.

3) $\theta$ and $r$ affect the fatigue life of the welded joint by changing the stress concentration factor of the joint. When $\mathrm{r}$ increases from 0.5 to $4 \mathrm{~mm}, \mathrm{~K}_{\mathrm{t}}$ decreases from 1.763 to 1.201 , and the rate of decrease is $31.88 \%$. The fatigue life $\mathrm{N}$ of the butt joint calculated by the finite element method increases from $1.12 \times 10^{5}$ to $1.35 \times 10^{6}$, and the fatigue life is extended by 12.1 times.

4) When $\theta$ is $30^{\circ}$ and $\mathrm{r}$ is $0.5 \mathrm{~mm}$, the average life of the joint fatigue test is $0.126 \times 10^{6}$, and the fatigue life calculated by finite element is $0.112 \times 10^{6}$, the difference between the two is $12.5 \%$; When $\mathrm{r}$ is $4 \mathrm{~mm}$, the average life of the joint fatigue test is $1.547 \times 10^{6}$, the finite element calculation is $1.356 \times 10^{6}$, the difference between the two is $14.1 \%$. In both cases, the fatigue life error of theoretical calculation and test is less than $15 \%$. The effect of joint geometric parameters on fatigue life obtained by finite element calculation has important guiding significance for actual structural fatigue.

\section{Acknowledgments}

The project was supported by the National Natural Science Foundation of China (51265013), the Science Foundation of Jiangxi Province (20161BBE50072). 


\section{References}

[1] Huo LX. Fracture Properties and Evaluation of Welded Structures. Beijing: China Machine Press, 2000:221.

[2] Teng CX, Zuo S, Zhao K, Lan XW, Zhu HY, Zhang YB. Progress in Surface Modification of Welded Joints. Surface Technology, 2014, 43(4):149-157.

[3] He BL, Yu YX, Shi JP, Yu HH. Effect of Stress Concentration Factor on Fatigue Life of 16MnR Steel Butt Joint of Bogie. China Railway Science, 2013, 34(6):89-92.

[4] Esderts A, Willen J, Kassner M. Fatigue strength analysis of welded joints in closed steel sections in rail vehicles. International Journal of Fatigue, 2012(34):112-121.

[5] He BL, Jiang MM, Yu YX, Li L. Microstructure and Fatigue Property of MB8 Magnesium Alloy Cross Welded Joint with Ultrasonic Impact. Journal of Materials Engineering2018,46(10):70-76.

[6] Roy S, Fisher JW, Yen BT. Fatigue resistance of welded details enhanced by ultrasonic impact treatment (UIT). International Journal of Fatigue, 25(2003):1239-1247.

[7] He BL, Yu YX, Yu HH, Jiang MH, Shi JP. Effect of Ultrasonic Impact on the Surface Microstructure and Fatigue Properties of welded Cross Joint for Train Bogie.Transactions of the China Welding Institution, 2013, 34(8):51-54.

[8] Pedersen MM, Mouritsen O, Hansen MR, Andersen JG, Wenderby J. Comparison of Post Weld Treatment of High Strength Steel Welded Joints in Medium Cycle Fatigue. Welding in the world, 2010, 54(7-8):208-217. 